\title{
Impact fatigue behavior of superelastic NiTi shape memory alloy wires
}

\author{
J. Zurbitu ${ }^{\mathrm{a}, e, *}$, R. Santamarta ${ }^{\mathrm{b}}$, C. Picornell ${ }^{\mathrm{b}}$, W.M. Gan ${ }^{\mathrm{c}}$, H.-G. Brokmeier ${ }^{\mathrm{d}}$, J. Aurrekoetxea ${ }^{\mathrm{a}}$ \\ a Mechanical and Industrial Production Department, Mondragon Unibertsitatea, Loramendi 4, 20500 Mondragon, Spain \\ b Department of Physics, Universitat de les Illes Balears, Cra Valldemossa, km 7.5, 07122 Palma de Mallorca, Spain \\ c GKSS Out Station at FRM-II, D85747 Garching, Germany \\ d Institute for Materials Science and Engineering, Clausthal University of Technology, D38678 Clausthal-Zellerfeld, Germany \\ e Mechanical Design Department, Ikerlan-IK4, P`. J. Ma․ Arizmendiarrieta 2, 20500 Mondragon, Spain
}

\section{A R T I C L E I N F O}

\section{Article history:}

Received 28 June 2010

Received in revised form

28 September 2010

Accepted 29 September 2010

\section{Keywords:}

Shape memory alloy

NiTi

Superelasticity

Impact

Cyclic deformation

Fatigue

Martensitic transformation

\begin{abstract}
A B S T R A C T
Superelastic cyclic behavior of NiTi wires was studied by cyclically deforming several samples at impact strain rates on the order of $10 \mathrm{~s}^{-1}$, using an instrumented tensile-impact device. The stress-strain cycles were performed up to different maximum strain ratios in order to study the cyclic impact fatigue for the incomplete, complete stress-induced martensitic transformation, and for the elastoplastic deformation of the martensitic phase. Impact results show that the stress-induced martensitic transformation stresses decrease with the number of cycles, although this decrease is lower than that obtained in cycling fatigue experiments performed at low strain rates. This suggests that the increment of the dislocation density, responsible for the stress reduction, depends on the strain rate applied during deformation. Moreover, the near-adiabatic condition fulfilled when deforming at high strain rates, promoting higher stress-induced martensitic transformation stresses during cycling at impact than the ones reached at low strain rates. In addition, the dissipated energy per cycle is also affected by the strain rate, being at impact $10-15 \%$ lower than the values obtained when the deformation occurs in isothermal conditions, that is at strain rates lower than $10^{-4} \mathrm{~s}^{-1}$
\end{abstract}

(c) 2010 Elsevier B.V. All rights reserved.

\section{Introduction}

NiTi shape memory alloys (SMA) are promising materials for impact applications because of their high damping capacity related to the hysteresis of the stress-induced martensitic (SIM) B2-B19' transformation. These alloys show the ability to dissipate a large fraction of the energy supplied to the system with small plastic deformation, which makes SMAs highly attractive for energy absorption/storage, impact damping or seismic protection [1-3]. In many of these applications, SMAs are demanded to work under cyclic impact loading, then reducing the service life and/or modifying the material properties in comparison to quasi-static cyclic loading. Moreover, SMAs are often required to be "trained" before use in order to obtain more stable and well known mechanical behavior; this "training" procedure consists of deforming repeatedly the material until more stable characteristics are achieved [4]. Therefore, in order to develop the use of SMAs under impact cyclic conditions, a better knowledge of the impact fatigue process is needed.

\footnotetext{
* Corresponding author at: Mechanical Design Department, ikerlan-IK4, P. J. M $\stackrel{a}{-}$. Arizmendiarrieta 2, 20500 Mondragon, Spain. Tel.: +34 943712400 .

E-mail address: jzurbitu@ikerlan.es (J. Zurbitu).
}

There are some previous works dealing with cyclic fatigue of SMAs under different conditions, especially with NiTi alloys, because of their enhanced mechanical properties, longer fatigue life and better corrosion resistance in comparison with other SMAs [5]. Some of these studies report cyclic response of NiTi for martensitic initial conditions [6], but most of them deal with cyclic superelastic behavior of the SIM transformation [7-12]. The SIM transformation has been usually performed with specimens in form of wire, from 0.7 to $2 \mathrm{~mm}$ in diameter, because they show higher strength and damping properties compared with larger diameter wires [10]. The specimens are cycled up to 100 times, which is usually enough to obtain a stable behavior $[7,10]$, but some of them focus on the fatigue until the 1000th cycle [11]. Concerning the strain rate at which fatigue takes place, up to now cycling research of NiTi SMAs has focused on tensile behavior at low strain rates, from $10^{-4}$ to $10^{-3} \mathrm{~s}^{-1}$. The cyclic characterization for higher strain rates has been carried out by a few groups, mostly limited to the order of $10^{-1} \mathrm{~s}^{-1}[3,12,13]$. Higher strain rates, on the order of $10^{3} \mathrm{~s}^{-1}$, have recently been achieved using Split Hopkinson Pressure Bar technique (S.H.P.B.), but only in compression [14,15]. Therefore, there is a lack of knowledge concerning cyclic fatigue of NiTi SMAs at impact strain rates on the order $10^{-1}-10^{2} \mathrm{~s}^{-1}$, especially in the tensile configuration.

The effects of cyclic loading fatigue at quasi-static strain rates on the NiTi mechanical properties are already well known. During 


\section{D Detector}
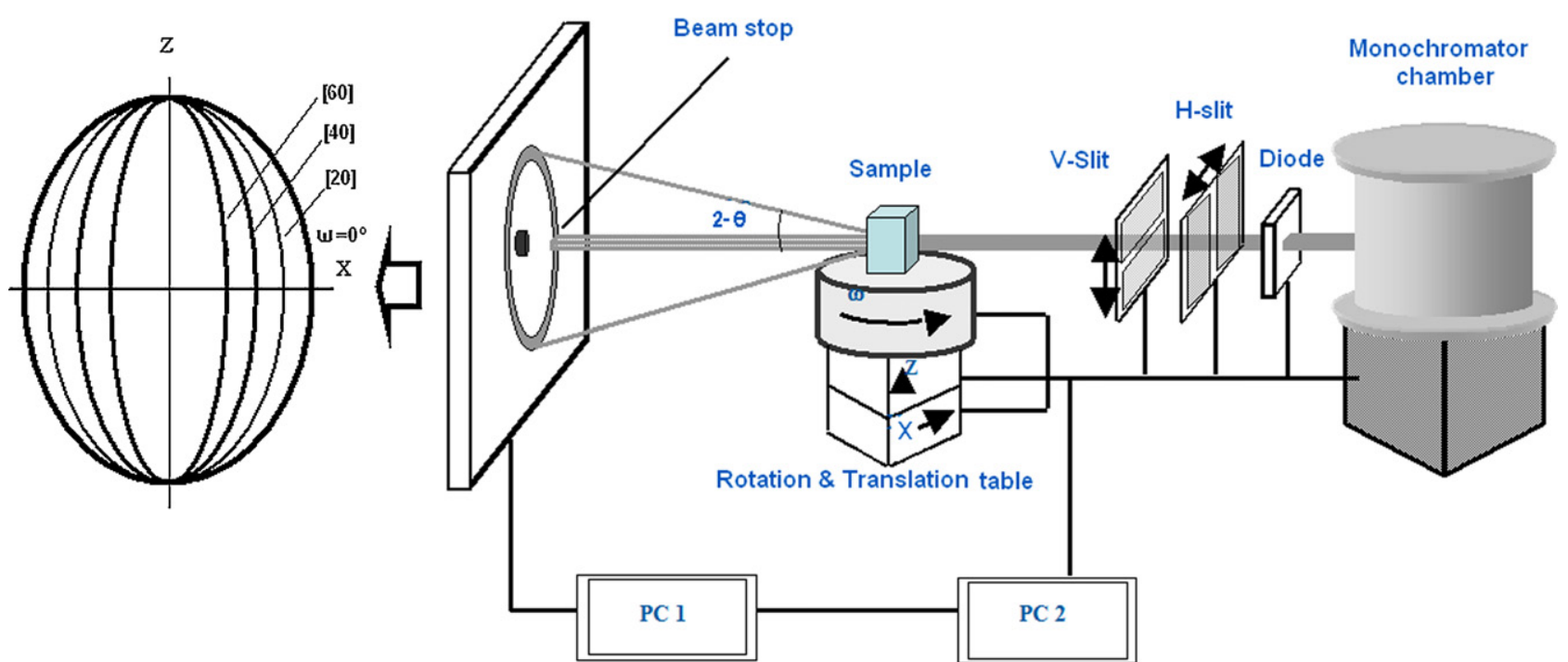

Fig. 1. High energy synchrotron diffractometer set-up (right) and the representation of a pole figure using Debye-Scherer rings at different $\omega$ angles (left).

cyclic loading, not only forward but also reverse transformation stresses decrease, the former more than the latter $[4,16,17]$. Thus, the stress-strain hysteresis diminishes dissipating smaller amounts of energy, but also a gradually increase of the irreversible plastic strain is observed. These effects are more evident during the first cycles and trend to stabilize as the number of cycles increases as a consequence of the internal stress fields and martensite stabilization caused by the dislocations piled up around defects during the cycling movement of the interface between the austenitic and martensitic phases $[4,16]$. Although the cyclic behavior of superelastic NiTi at quasi-static strain rates is already known, there is no information about cyclic deformation at impact, when the near-adiabatic nature of the process is fulfilled. Then, it would be interesting to understand the deformation response of the B2-B19' transformation at impact fatigue, in order to improve and optimize the design of impact applications under cyclic deformation. Therefore, the aim of this work is to compare the fatigue evolution of the low strain rate range with the impact strain rate range by studying the fatigue behavior of NiTi wires at impact strain rates, in terms of transformation stresses and strain energies (dissipated, deformation and recoverable) and the fatigue behavior at the limit of the low strain rate range in order to establish the differences of the fatigue evolution between the low and the impact strain rates ranges.

\section{Experimental method and material}

\subsection{Material}

A commercial NiTi (50.9 at.\% $\mathrm{Ni}$ ) in form of wire of $0.5 \mathrm{~mm}$ in diameter and austenitic grain size of $15-20 \mu \mathrm{m}$, purchased from@medical technologies (AMT), ref. NT09, was selected for the experimental tests carried out in this work. The austenitic finish temperature $\left(A_{\mathrm{f}}\right)$ determined by DSC measurements is $267 \mathrm{~K}$, hence this alloy will be in the austenitic phase at room temperature and will exhibit superelastic behavior under stress.

\subsection{Experimental scheme and techniques}

In order to study the fatigue behavior of NiTi wires, virgin specimens were loaded-unloaded up to 100 cycles. Following this procedure, three set of tests were carried out achieving different maximum strains (4\%,6\% and $9 \%$ ) before unloading. This scheme was repeated for two different strain rates, one at impact, on the order of $10 \mathrm{~s}^{-1}$, and another at a strain rate about two orders of magnitude lower, just at the limit of the conventional tensile test techniques, in order to study the transition behavior from the low strain rate to the impact range. Impact tests were carried out with an instrumented tensile impact device which is capable to obtain the stress-strain characteristics at impact strain rates. For each set of the impact fatigue tests, a specimen of $80 \mathrm{~mm}$ in length was deformed with the same impact energy for each cycle; the impact data were recorded after each test. From these data, stress-strain curves were obtained as detailed in Ref. [18]. Impact experiments were performed with a striker mass of $1.098 \mathrm{~kg}$ and three different impact velocities $(0.77,1.01$ and $1.21 \mathrm{~m} / \mathrm{s})$, in order to achieve the maximum strains detailed above. The sample is attached between a fixed grip and a mobile grip, and an impactor hits the mobile grip deforming the sample at high strain rates. The stress developed in the sample is measured at the fix grip by a piezoelectric sensor and the strain is obtained from the integration of the velocity measured at the mobile grip by a non-contacting laser based sensor. For more detailed information about this experimental technique see Ref. [18]. Strain controlled tests carried out at low strain rates were performed in universal screw-driven testing machines (Instron 4206 and Zwick Z100) on specimens of $50 \mathrm{~mm}$ in length. All tests were carried out at room temperature.

Texture measurements were carried at the high-energy GKSS - materials science beam line HARWI-W2@Hasylab/Hamburg. The basic layout of such a high-energy diffractometer is shown schematically in Fig. 1. A monochromator selects a monochromatic beam out of the white spectrum, Harwi-II is equipped with a double monochromator. This monochromatic beam is guided by a computer driven slit system to the polycrystalline sample, where diffraction takes place. The diffraction diagram is registered in a Mar345 area detector. The texture measurements were carried out in step of $5^{\circ}$ in $\omega$ rotation from $-90^{\circ}$ to $90^{\circ}$ for complete pole figure at a wavelength of $0.01625 \mathrm{~nm}$.

\section{Results and discussion}

\subsection{Strain rate effect}

Fig. 2 shows the evolution of the superelastic behavior as a function of the strain rate from the quasi-static to the impact range. At 


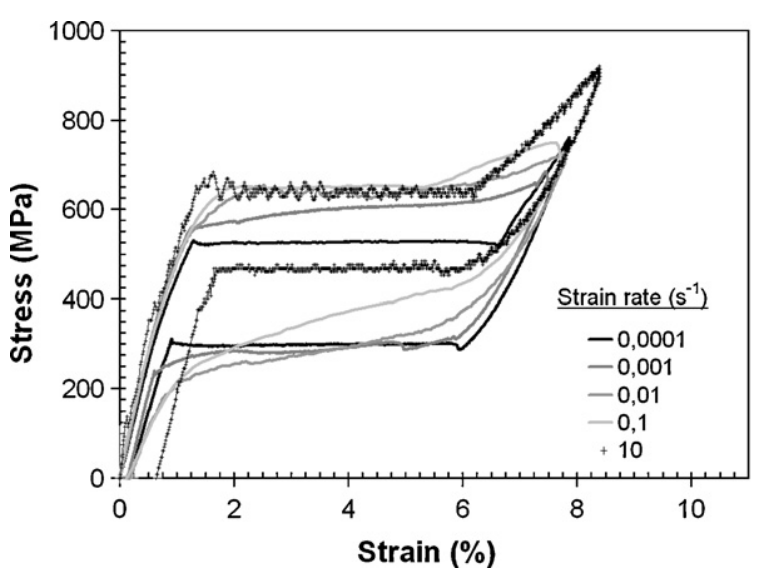

Fig. 2. Stress-strain curves at different strain rates.

strain rates lower than $10^{-4} \mathrm{~s}^{-1}$, the SIM transformation occurs at constant stress since all the heat generated/absorbed during the forward/reverse SIM transformation can be exchanged with the grips and with the surroundings. As the strain rate is increased, this process cannot be completely fulfilled, and part of the heat transfer modifies the temperature of the sample during the transformation, and therefore its characteristic stress [19]. Finally, at impact, the overall deformation process can be considered near-adiabatic, i.e., almost all the heat generated during the SIM transformation is spent in warming up the entire sample. Once the deformation process is near-adiabatic, the temperature may be rather constant during the deformation and higher than at the beginning of the test. Therefore, the transformation stresses will be also constant during transformations and higher as compared to the ones obtained at quasi-static strain rates [20].

The high strain rates developed at impact heats quickly the transformation zone until a maximum temperature which is function of the transformation enthalpy and the specific heat, as is shown in Eq. (1), where $C_{\mathrm{e}}$ is the specific heat and $\Delta H_{\mathrm{A}-\mathrm{M}}$ the transformation enthalpy [21]. This temperature cannot be overcome since the transformation enthalpy is finite, so temperature is kept constant during the transformation.

$\Delta T=\frac{\Delta H_{\mathrm{A}-\mathrm{M}}}{C_{\mathrm{e}}}$

The amount of energy dissipated during a loading-unloading cycle $\left(W_{\mathrm{d}}\right)$ was calculated as the area inside the entire $\sigma-\varepsilon$ loops (Fig. 3). This dissipated energy strongly depends on the strain rate, as shown in Fig. $4 . W_{\mathrm{d}}$ remains constant at strain rates below the

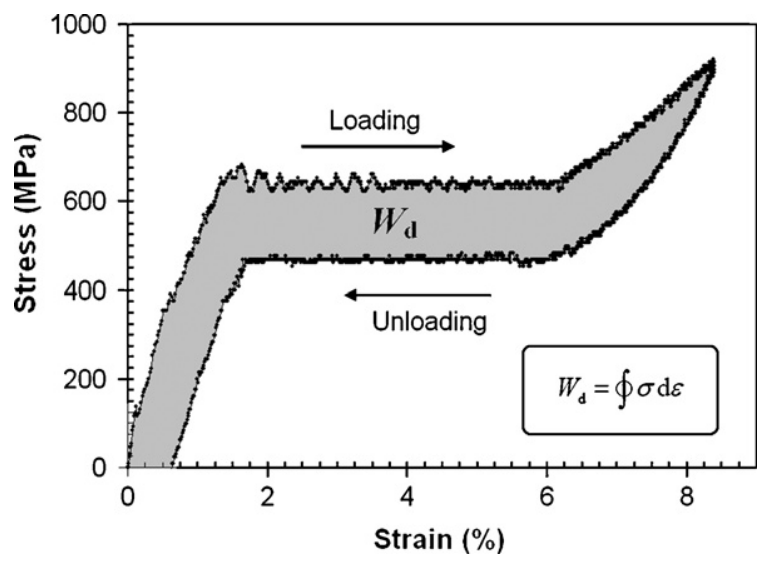

Fig. 3. Stress-strain diagram showing the calculation of the dissipated energy $\left(W_{\mathrm{d}}\right)$.

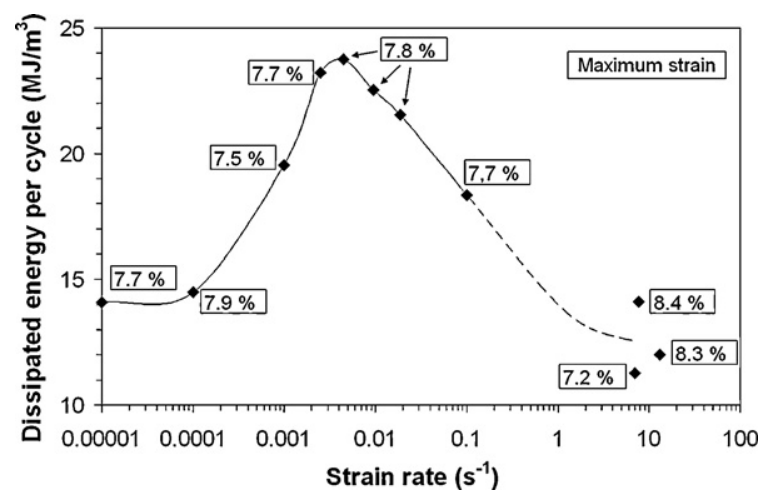

Fig. 4. Dissipated energy for similar loading-unloading cycles carried out at different strain rates.

limit at which the deformation process may be considered as an isothermal process $\left(10^{-4} \mathrm{~s}^{-1}\right)$. However, as the strain rate increases, $W_{\mathrm{d}}$ raises since the rate at which the SIM transformation stresses increase is higher during the loading than that during the unloading. This tendency changes above a certain strain rate where $W_{\mathrm{d}}$ is maximum (between $10^{-3}$ and $10^{-2} \mathrm{~s}^{-1}$ ) and finally it seems to reach a stable value at impact, which is slightly lower than the ones obtained at the isothermal limit (lower strain rates) because. $W_{\mathrm{d}}$ changes as a result of the transformation stress changes due to the temperature variations during the martensitic transformation [21]. While at intermediate strain rates the temperature during the reverse transformation may decrease, (decreasing so the transformation stresses), at impact it rises, increasing the reverse transformation stresses level and so reducing $W_{\mathrm{d}}$.

\subsection{Impact fatigue behavior}

The three sets of stress-strain curves obtained from the cycle fatigue tests, up to $4 \%, 6 \%$ and $9 \%$ in strain, are shown in Figs. 5-7, respectively: an incomplete SIM transformation can be observed in Fig. 5 while a complete SIM transformation is presented in Figs. 6 and 7. In Fig. 7 also the elastoplastic deformation of the martensitic phase is reached showing plastic strains after unloading. For the three cases, the behavior during the loading of the first

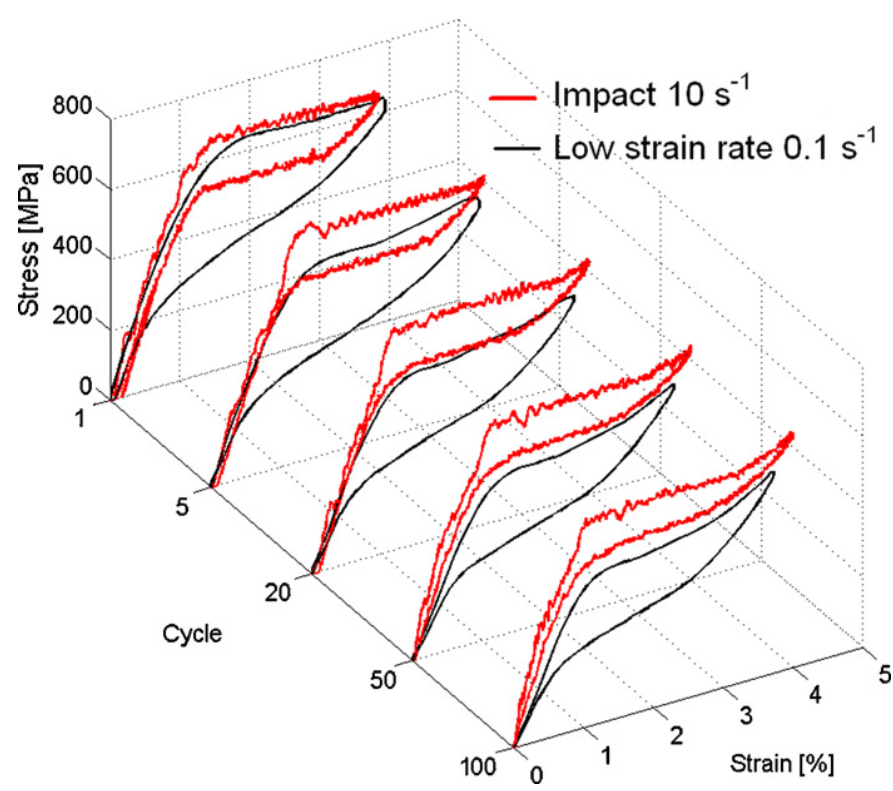

Fig. 5. Stress-strain curves under cyclic loading up to $4 \%$ in strain. 


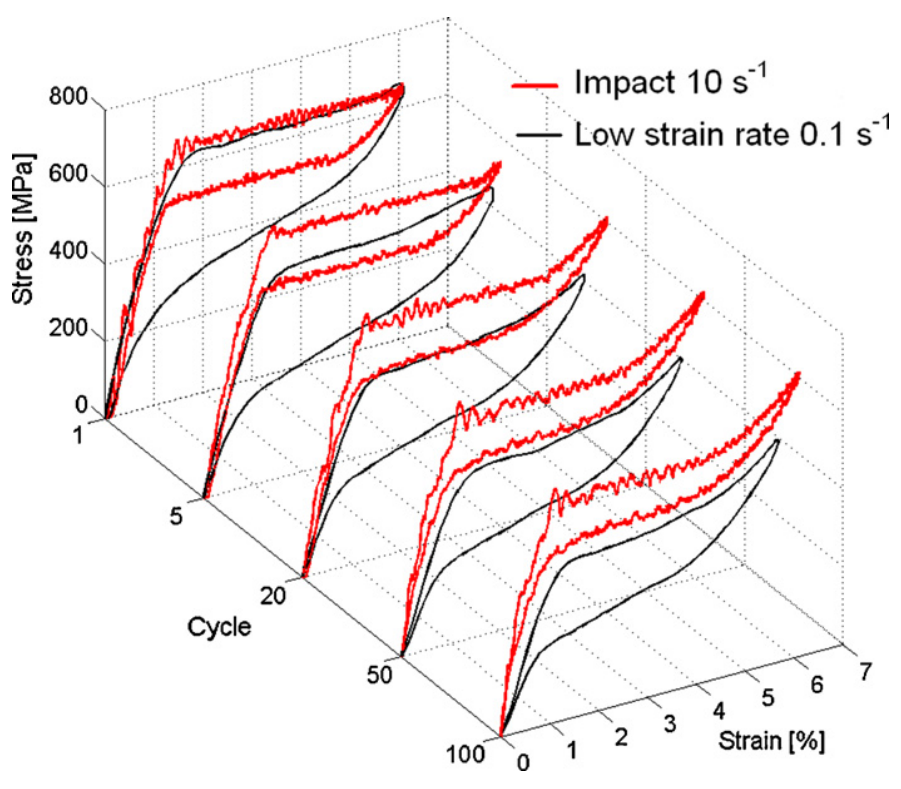

Fig. 6. Stress-strain curves under cyclic loading up to $6 \%$ in strain.

cycle is rather similar both for impact and low strain rate tests whereas the unloading path differs; it is rather constant at impact, while it diminishes at $0.1 \mathrm{~s}^{-1}$, due to the temperature change of the sample, as is shown in [21]. Impact tests performed until 9\% maximum strain values show, after unloading, a permanent strain related to the plastic deformation induced in the sample for the high stresses applied at the end of the loading process, which produce a greater number of slips.

Fig. 8a shows that the Upper Plateau Stress (UPS), measured as the forward SIM transformation stress at 3\% strain during loading, decreases with the number of cycles, being the decrease higher as greater is the maximum applied strain. Analogously, Fig. 8b shows the Lower Plateau Stress (LPS), measured as the reverse SIM transformation stress at $2.5 \%$ strain during unloading, also decreases when the number of cycles increases. A similar feature occurs at very low strain rates, on the order of $10^{-4} \mathrm{~s}^{-1}$, as reported in $[9,22,23]$. After the XRD experiments that will be shown in Section 3.4, this stress decrease has been associated with the appearance of small amounts of stabilized martensite originated from localized slips produced by the increment of the dislocation density during

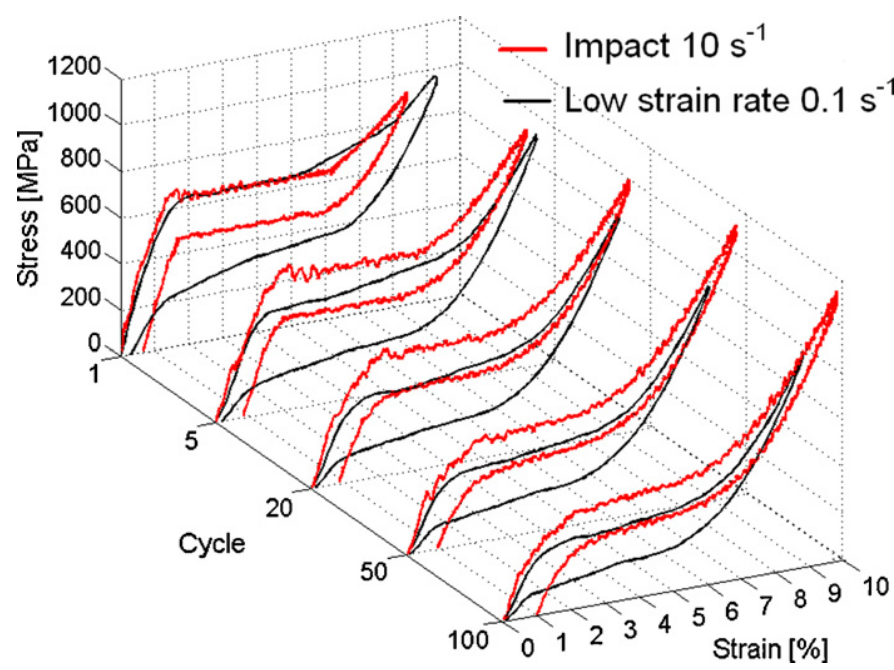

Fig. 7. Stress-strain curves under cyclic loading up to $9 \%$ in strain.
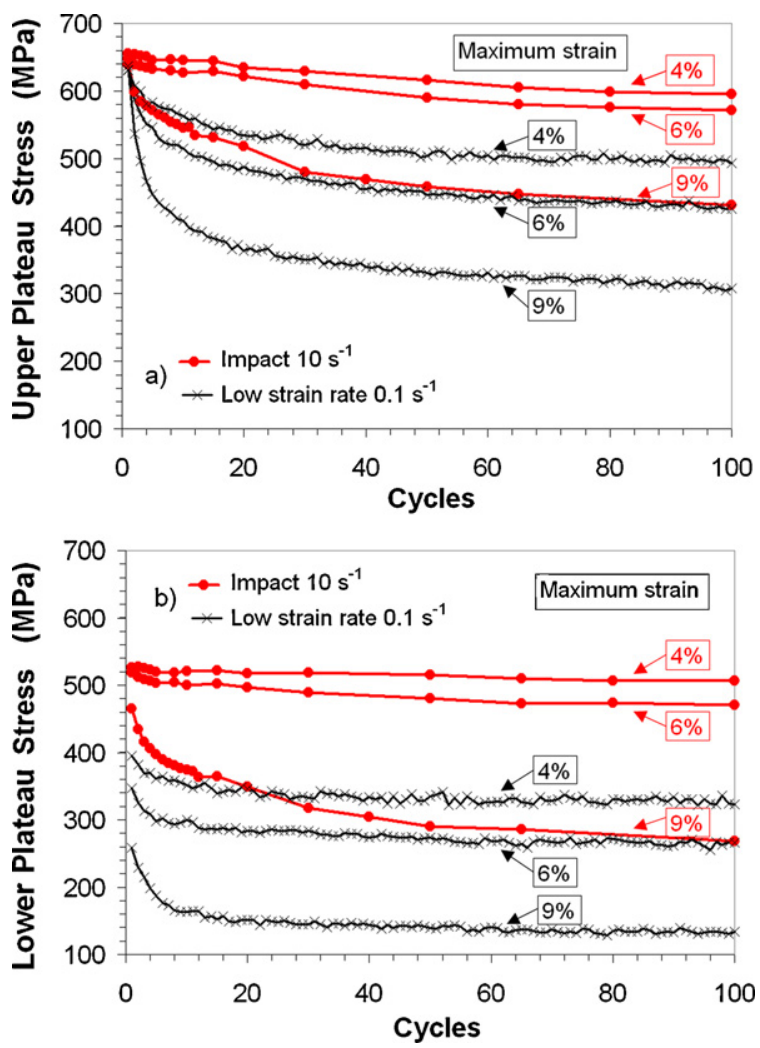

Fig. 8. Effect of cycling on the martensitic transformation stresses, (a) forward SIM transformation stresses, (b) reverse SIM transformation stresses.

successive movements of the interface between the austenitic and martensitic phases $[4,16]$.

Additionally, at impact, the decrement of the transformation stresses with the number of cycles is lower than that at low strain rates (Fig. 8) and it is significant only for tests with elastoplastic deformation of the martensitic phase, i.e. up to $9 \%$ in strain. This behavior confirms that the degradation mechanisms while cycling at impact are different from those at lower strain rates because, although the SIM mechanism also occurs at impact, the increment of dislocation density during cycling probably depends on the strain rate as well as on the maximum applied strain. As it is shown in Fig. 7, for both deformation rates, the main decrement in the transformation stress with the number of cycles occurs during the first 20 cycles, whereas above the 50th cycle, the stress-strain response barely changes. Therefore, there is a kind of saturation with cycling because after each cycle it is more difficult to increase the dislocation density and correspondingly, the amount of stabilized martensite, then leading to a stable transformation path. At very low strain rates, on the order of $10^{-4} \mathrm{~s}^{-1}$, the mechanical stabilization has also been reported at a similar number of cycles [2].

Although the UPS is the same for the first cycle for all the strain rates, the final stress achieved after stabilization depends on the maximum strain achieved during prior cycles as function of the slip generated for the previous deformations (Fig. 8). The LPS may differ for the first cycle because it depends on the maximum strain achieved during forward transformation [24]. Then, these are important features whenever material must be "trained" to obtain stable behavior, or when the transformation stresses must be known for designing applications under impact loading conditions. At impact, the stress decrease after 100 cycles is slightly greater for the forward than for the reverse SIM transformation (Fig. 8), and this differs from the results obtained at lower strain 


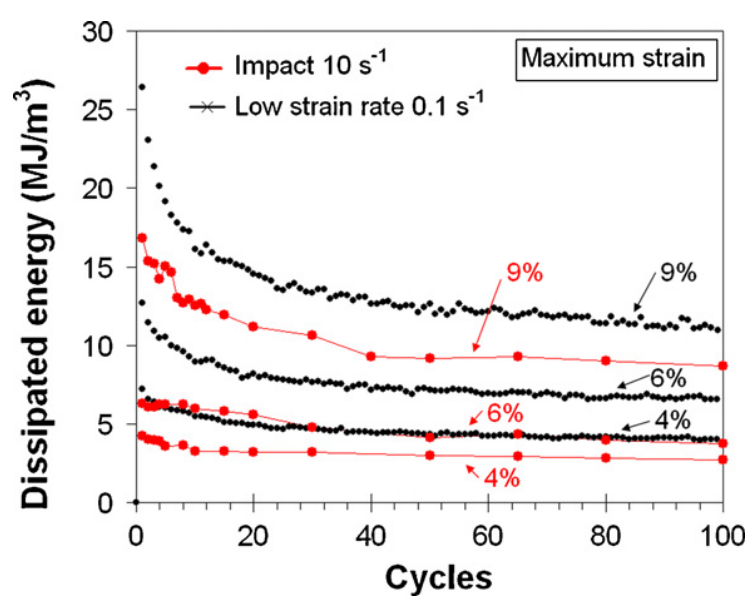

Fig. 9. Effect of cycling, up to different maximum strains $4 \%, 6 \%$ and $9 \%$, on dissipated energy.

rates in which the decrease of forward transformation stress is much greater than the reverse, as it has been observed in other works $[8,22]$.

\subsection{Dissipated energies after impact fatigue}

The evolution of dissipated energy during cycling at impact strain rates differs from that observed at lower strain rates (Fig. 9). At quasi-static strain rates, the decrease of the dissipated energy with cycling is higher, mainly due to the faster decrease of the forward transformation stresses with cycling in comparison to the ones of the reverse transformation stresses. After a few cycles, the dissipated energy tends to stabilize in a similar way to the transformation stresses. At impact, only the cycling fatigue with maximum strains exceeding that necessary for completing the SIM transformation, $9 \%$, may be considered as relevant as the one obtained at low strain rates. This is as a result of the similar decrement rate evolution of the forward and reverse transformation stresses with cycling. It is worth to mention that in case of comparing $W_{\mathrm{d}}$ at impact (near-adiabatic deformation process) and at a strain rate of $10^{-4} \mathrm{~s}^{-1}$ (isothermal deformation process) the values of $W_{\mathrm{d}}$ would be only slightly different, as is shown in Fig. 3.

\subsection{Deformation mechanisms}

In order to check the existence of stabilized martensite in the NiTi wires, XRD experiments were performed in undeformed samples, in samples after 100 cycles up to $10 \%$ strain at $0.1 \mathrm{~s}^{-1}$ and in samples after 50 cycles up to $11 \%$ strain at impact $\left(10 \mathrm{~s}^{-1}\right)$. The XRD pattern obtained for the impacted sample show small peaks close to the $\left(\begin{array}{lll}1 & 0\end{array}\right)_{\mathrm{B} 2}$ planes, which indicates that small amounts of martensite remain stabilized after impact cycling (Fig. 10). These needles of stabilized martensite could promote the growth of some specific variants along directions favorable to the external stress before the nucleation of new ones, then lowering the UPL and LPS. Moreover, as the stabilized B19' martensite remains without transforming back to the austenitic B2 structure after impact deformation, the superelastic strain available for the subsequent cycles is reduced, thus the elastoplastic deformation of the martensitic phase begins at earlier strains after each cycle, as observed in Fig. 7. Nevertheless, it has to be noted that the diffraction pattern of the sample cycled at $0.1 \mathrm{~s}^{-1}$ in Fig. 10 already shows slightly higher "tails" and width of the $(110)_{\mathrm{B} 2}$ peak. These tails could be attributed to the existence of stress fields associated to dislocations created along the "right" directions during cycling (without almost any retained martensite), which could lower the driving force to start the SIM

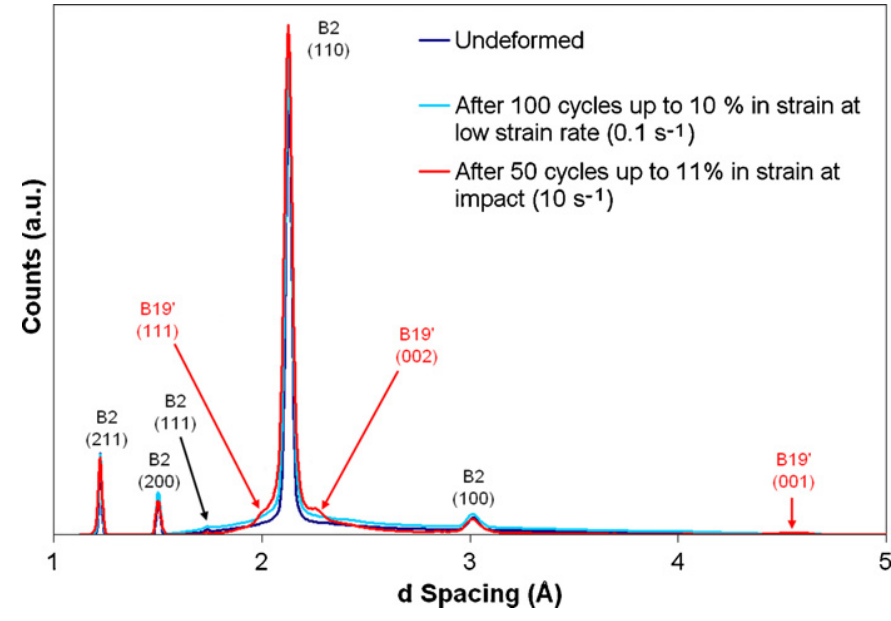

Fig. 10. Diffraction patterns of NiTi wire before and after impact damage with different strain rates.

transformation by promoting the growth of favorable variants, as observed in Figs. 5-7. Although the impact sample was subjected to less cycles than the one cycled at low strain rate, the former was deformed up to higher strains ( $1 \%$ more), so that the maximum stresses developed in the sample were higher, $1375 \mathrm{MPa}$ against $1100 \mathrm{MPa}$. Then, the stress fields created during cycling seem to decrease the SIM transformation stress, while the appearance of stabilized B19' martensite is more related to the localized slips formed during plastic deformation which occur at the highest stresses/strains.

\section{Summary}

The mechanical fatigue at impact strain rates, on the order of $10 \mathrm{~s}^{-1}$, of SIM transformation in superelastic NiTi SMA wires was experimentally studied in case of various maximum strain ratios. The main results obtained are summarized as follows.

The cyclic deformation of NiTi at impact changes the stress-strain response in a similar way that at low strain rates, that is decreasing the SIM transformation stresses due to the appearance of stress fields of dislocations and small amounts of stabilized B19' martensite. The role of the stabilized martensite, which appears when the stresses are high, is to promote the growth of martensitic variants along directions favorable to the external stress. The dislocation density increases with maximum stresses, that is, as more important is the degradation of the material, but also depends on the strain rate applied during deformation.

At impact, the decrement rate of the Upper Plateau Stress (UPS) as the number of cycles increases is only slightly larger than the Lower Plateau Stress (LPS), while at lower strain rates the decrement of the UPS is much greater than the LPS. The dissipated energy per cycle, $W_{\mathrm{d}}$, is also affected by the strain rate, being higher at the intermediate range of strain rates. The main decrease on SIM transformation stresses and $W_{\mathrm{d}}$ occurs for the first 20th cycles and the behavior is stabilized after the 50th cycle. However, the stable value achieved depends not only on the previous maximum strain achieved, but also on the strain rate at which it takes place.

\section{Acknowledgements}

The authors would like to thank the Basque Government (PI2008-07, IE08-229) and the Spanish Government (PSS-3700002008-13) for the financial support. 


\section{References}

[1] H. Funakubo, Shape Memory Alloys, Gordon and Breach, New York, 1984.

[2] H. Tobushi, E. Pieczyska, S. Gadaj, W.K. Nowacki, K. Hoshio, Y. Makino, Sci. Technol. Adv. Mater. 6 (2005) 889-894.

[3] M. Dolce, D. Cardone, Int. J. Mech. Sci. 43 (2001) 2657-2677.

[4] S. Miyazaki, T. Imai, Y. Igo, K. Otsuka, Acta. Metall. Mater. 17 (1986) 115120.

[5] T.W. Duering, K.N. Melton, D. Stockel, C.M. Wayman, Engineering Aspects of Shape Memory Alloys, Butterworth-Heinemann, London, 1990.

[6] W.M. Huang, H.K. Lim, J. Mater. Sci. Lett. 22 (2003) 1399-1400.

[7] J.M. Gong, H. Tobushi, K. Takata, K. Okumura, M. Endo, Mater. Sci. Forum. 394-395 (2002) 245-248.

[8] P. Malecot, C. Lexcellent, E. Foltete, M. Collet, J. Eng. Mater. Trans. ASME 128 (2006) 335-345.

[9] K. Tanaka, F. Nishimura, M. Matsui, H. Tobushi, P.H. Lin, Mech. Mater. 24 (1996) 19-30.

[10] A. Yawny, J. Olbricht, M. Sade, G. Eggeler, Mater. Sci. Eng. A 481-482 (2008) 86-90.

[11] H. Naito, J. Sato, K. Funami, Y. Matsuzaki, T. Ikeda, J. Intel. Mater. Syst. Struct. 12 (2001) 295-300.

[12] R. Desroches, J. McCormick, M. Delemont, J. Struct. Eng. 30 (2004) 38-46.

[13] D. Wolons, F. Gandhi, B. Malovrh, J. Intel. Mater. Syst. Struct. 9 (1998) 116-126.
[14] D.A. Miller, W.R. Thissell, G.T. Gray III, D.A.S. Macdougall, Stress-induced Martensitic Phase Transformations in NiTi Shape Memory Alloys During Dynamic Loading, 60, American Society of Mechanical Engineers, Aerospace Division (Publication) AD, 2000, pp. 51-63.

[15] S. Nemat-Nasser, W.G. Guo, Mech. Mater. 38 (2006) 463-474.

[16] S. Miyazaki, in: T.W. Duerig, K.N. Melton, D. Stoeckel, C.M. Wayman (Eds.), Engineering Aspects of Shape Memory Alloys, Butterworth-Heinemann Ltd., London, 1990, pp. 394-413.

[17] P.H. Lin, H. Tobushi, K. Tanaka, T. Hattori, M. Makita, J. Intel. Mater. Syst. Struct. 5 (1994) 694-701.

[18] J.Zurbitu, S. Kustov, G. Castillo, L. Aretxabaleta, E. Cesari, J. Aurrekoetxea, Mater. Sci. Eng. A 524 (2009) 108-111.

[19] J.A. Shaw, S. Kyriakides, J. Mech. Phys. Solids 43 (1995) 1243-1281.

[20] J. Zurbitu, G. Castillo, I. Urrutibeascoa, J. Aurrekoetxea, Mech. Mater. 41 (2009) $1050-1058$.

[21] J. Zurbitu, S. Kustov, A. Zabaleta, E. Cesari, J. Aurrekoetxea, in: C. Cismasiu (Ed.), Shape Memory Alloys, Rijeka, 2010. ISBN 978-953-307-106-0.

[22] H. Tobushi, Y. Shimeno, T. Hachisuka, K. Tanaka, Mech. Mater. 30 (1998) $141-150$.

[23] G. Eggeler, E. Hornbogen, A. Yawny, A. Heckmann, M. Wagner, Mater. Sci. Eng. A: Struct. A378 (2004) 24-33.

[24] J. Zurbitu, G. Castillo, I. Urrutibeascoa, J. Aurrekoetxea, J. Mater. Eng. Perform. 18 (2009) 600-602. 